\title{
Engaging Underrepresented Adolescents in Authentic Scientific Settings: Scientist Role Models and Improving Psychosocial Outcomes
} Noé Rubén Chávez ${ }^{1}$, Alexandra Race ${ }^{2}$, Marisa Bowers ${ }^{3}$, Susan $\mathrm{Kane}^{3}$, and Christopher Sistrunk ${ }^{3}$

\author{
${ }^{1}$ Charles R. Drew University of Medicine and Science, Los Angeles, CA; ${ }^{2}$ University of California Santa Cruz; and ${ }^{3}$ City of Hope Comprehensive Cancer Center, Los \\ Angeles, CA
}

Keywords: Science Education, Underrepresented Students, Science Role Models

Publication Date: November 11, 2019

DOI: https://doi.org/10.15695/jstem/v2i1.18

\begin{abstract}
There is a critical need for more effective comprehensive programs to increase the number of underrepresented minority students pursuing scientific careers. Science education often is fragmented, delivered with single-focused approaches - traditional classroom lectures, or hands-on-activities, or conducting research. The current paper examines a comprehensive biomedical research program that integrated classroom teaching, hands-on-activities, conducting a research study, and mentoring from scientists in authentic scientific settings. We assessed short-term psychosocial outcomes and long-term academic outcomes in the participants, largely underrepresented minority high school students. The psychosocial outcomes assessed pre and post program include: knowledge of science pathways, attitudes toward science, self-efficacy in science, and scientific communication skills. Post-program results showed an increasing trend for knowledge of science pathways, attitudes toward science, and self-efficacy in science. Post-program, students also reported significant increases in feeling they had role models in science. A long-term assessment was conducted examining participating students' college attendance and majoring in a STEM field. The long-term assessment showed that $77 \%$ of students were attending college, $79 \%$ were majoring in STEM, and 75\% were planning to pursue additional higher education. Findings provide evidence for the short-term and long-term benefits of a comprehensive biomedical research program conducted in an authentic scientific setting.
\end{abstract}

\section{INTRODUCTION}

The United States is increasingly more ethnically/racially diverse, yet there is a persistent significant disparity in ethnic/racial representation in the sciences (Asai and Bauerle, 2016; Chemers et al., 2011; Garrison, 2013; Upshur et al., 2017). There are various multi-level factors contributing to the lack of diversity in the sciences, including broader historical and societal level factors, such as poverty and racism (Morales-Doyle, 2017; Saetermoe et al., 2017), along with more specific factors, including a lack of access to quality educational opportunities and professional mentors (Rogers-Chapman, 2014; Upshur et al., 2017). Therefore, there is a critical need for more effective comprehensive programs that apply a diversity of strategies to target the multiple needs and assets of underrepresented minority students (Richardson et al., 2017). Well-designed comprehensive programs in science education outside of formal school science curriculums that are implemented in authentic scientific settings have been found effective in addressing the multiple factors influencing students' pursuit of scientific careers (Ashley et al., 2017; Crump et al., 2015; Winkleby and Ned, 2010; Winkleby et al., 2014). A comprehensive program can be defined as including at least two and preferably more of the follow- ing components: a) lectures on particular science topics, b) hands-on science related activities, c) student participation in developing, conducting, or evaluating a research study, d) presentation of research results, and e) mentoring from scientists (Ashley et al., 2017). Many comprehensive programs are implemented for college students or for high school students who are already accepted into college (e.g., Summer Bridge Programs) (Ashley et al., 2017; Salto et al., 2014). There is a need for additional comprehensive programs that are implemented earlier for underrepresented minority high school or younger students.

Comprehensive science education or STEM programs implemented in authentic scientific settings target the development of various scientific technical skills, but also often aim to improve particular psychosocial factors/constructs associated with engagement (Chemers et al., 2011; Knox et al., 2003). Psychosocial factors, broadly speaking, refer to psychological constructs such as knowledge, attitudes and beliefs associated with behavior change (Lippke and Ziegelmann, 2008), where self-efficacy or the belief in one's capability of engaging in a behavior has been one key process (Bandura, 2001). For example, the knowledge, attitudes, 
and beliefs that students hold of science, specific activities related to science, or their capabilities of conducting those activities (i.e., self-efficacy in science), will influence their behaviors in science (e.g., engaging in research, interacting with researchers, pursuing a science major) (Hsu and Roth, 2010; Rahm and Moore, 2016). Such psychosocial factors are closely linked to students' sense of science identity, or how they see themselves in the sciences (Aschbacher et al., 2009; Byars-Winston and Rogers, 2019; Robinson et al., 2018; White et al., 2019). To improve academic behavior and other related behavior that is necessary for students to become interested in science and sustain their interest, interventions are needed that enhance their scientific knowledge, science communication skills, attitudes toward science, or self-efficacy in conducting science, among other psychosocial constructs (Aschbacher et al., 2009; Chemers et al., 2011). There is empirical evidence showing that students' science identity is tied to some of these psychosocial outcomes, including self-efficacy in science or other outcomes such as intentions to pursue careers in science (Byars-Winston and Rogers, 2019; Robinson et al., 2018). These findings highlight the significance of understanding science as not solely shaped by the technical knowledge and skills but also influenced by the psychosocial dynamics that shape how scientists view themselves, collaborate with others, mentor new and developing scientists, and engage in other dynamic processes of science.

Although more traditional curriculums in school settings may still be able to increase knowledge in an area of science, the goal to enhance students' attitudes, self-efficacy, or identity in understanding and doing science arguably requires additional activities - including hands-on tasks, mentoring, and other opportunities to engage in research with current scientists in authentic scientific/laboratory settings (Burgin et al., 2012; Sadler et al., 2010; Salto et al., 2014; White and Usher, 2015). Furthermore, knowledge and appreciation of science is enhanced when students are more fully engaged in conducting science projects with scientists who can provide mentorship and share insights from their own careers and educational journey. Additionally, skills related to science communication, such as knowing the audience, are an important outcome for preparing students for a career in the sciences and improving scientific literacy (Mercer-Mapstone and Kuchel, 2017; Spektor-Levy et al., 2009). Various science education efforts have emphasized the significance of preparing students to develop and strengthen the skill of communicating scientific procedures, results and knowledge in general to not just scientists but the public as fundamental to one's goals as a scientist (Eeds et al., 2014; Campbell et al., 2000; Krieger and Gallois 2017; Spektor-Levy et al., 2008).

The close interactions that students experience when working with scientists or advanced students in laboratory/ research settings stimulate the social, collaborative, and relational aspects of science that are an essential component of working collaboratively as a scientist. A National Academies of Science report (National Research Council, 2007) highlighted three areas that science educators should aim to teach students: a) knowledge about the natural world, b) understanding the process by which that knowledge is generated, and c) an appreciation of the social and participatory nature of science (Newcombe et al., 2009). Studies evaluating the elements of science programs that are most effective reveal that participating students have highlighted the peer and staff relationships as one of the most important benefits of programs (Fields, 2009; Salto et al., 2014). A review of multiple studies examining research apprenticeships found that the successes of apprenticeship type programs and environments are tied to the direct interaction of students with scientists in authentic scientific settings (Sadler et al., 2010). Some of the studies with high school students (Stake and Mares, 2005; Templin et al., 1999) reviewed in this paper yielded data indicating increased confidence and self-efficacy in "doing science" after participation in a science apprenticeship program (Sadler et al., 2010).

There is evidence that participation in science apprenticeship programs in authentic scientific settings increases the likelihood that students will identify more strongly as a "scientist" (Robnett et al., 2015), which is critical for their decision-making to pursue a college major or career in science. An in-depth case study of underrepresented youth in a STEM program revealed the significance of focusing on students' life experiences, identity, and challenges as they navigate through learning about science and pursuing a pathway of higher education in science (Rahm and Moore, 2016). Self-confidence and motivation are essential leadership qualities in science and medicine, and these take time for students to develop. It is essential for students to have close supportive mentors who can help them navigate through the challenges of learning about science and developing into a "scientist" (Rohrbaugh and Corces, 2011; Salto et al., 2014). Exposing students to scientist mentors from early on can help boost their confidence or self-efficacy in engaging in scientific studies (Sadler et al., 2010). Self-efficacy, which refers to students' belief that they are capable and can be successful in "doing science," is one fundamental element in positively influencing students to pursue careers in the biomedical sciences or other scientific disciplines (Byars-Winston et al., 2010; Robnett et al., 2015; Salto et al., 2014).

One study examined the relevance of both identity and self-efficacy in science for ethnically diverse undergraduate, graduate, and postdoctoral fellows (Chemers et al., 2011). The study found that among undergraduate students, both self-efficacy and identity as a scientist were critical aspects that quality mentoring helped develop in students, which in turn enhanced their commitment to a career in science 
(Chemers et al., 2011). Another study evaluating a summer research program with both high school and undergraduate underrepresented minority students also found that their engagement in a real science project, along with mentoring, was associated with greater self-efficacy in conducting science and an increased confidence and motivation to become a scientist (Salto et al., 2014). A consistent finding across research is that science programs where students are engaged in working closely with scientists in real world settings can effectively improve psychosocial outcomes that are key for learning about science and seeking to pursue science college majors or careers in science (Burgin et al., 2012; Sadler et al., 2010; Salto et al., 2014).

The current study examines whether a biomedical summer apprenticeship program improved various psychosocial outcomes: knowledge of pathways into science, self-efficacy in science, attitudes towards science, and scientific communication skills. Furthermore, a longitudinal assessment was conducted to determine the long-term results of the summer biomedical program - specifically examining if students were attending college, pursuing science majors, and reporting academic persistence.

\section{METHODS}

Description of Program, Setting, and Participants. The high school summer biomedical research program discussed in this paper is part of a broader, comprehensive science education initiative, the San Gabriel Valley Science Education Partnership Award Collaborative (SGV SEPAC). Supported by a Science Education Partnership Award from the National Institutes of Health, the SGV SEPAC was implemented by City of Hope, a comprehensive cancer center located in Duarte, CA, within Los Angeles County. City of Hope collaborated with the Duarte Unified School District (DUSD) to engage students who were predominantly underrepresented minorities and from low-income neighborhoods within Duarte. The student population at DUSD is mostly Latinx $(70.4 \%)$ and most students qualify for a reduced or free lunch (71.6\%) (Ed-Data.org, 2019). The partnership aimed to increase minority student access to and interest in biomedical careers. It is important to note that we have established several programs with multiple touch points, starting in elementary and going through high school, to increase interest in science within DUSD. The SEPAC High School Summer Research Program (the program) was held during the summers at City of Hope from 2012-2016. The goal was for this program to be the culmination of multiple years of science interaction with the DUSD students.

The program was offered to students attending the local high school, Duarte High School, who had just completed 10 th or 11th grade and would attend 11 th or 12 th grade after the end of the summer. Students were recruited to the program through advertisement by the local high school science teachers, through the daily bulletin, and by classroom visits from City of Hope staff. Students were selected through an application process in which they reported a list of science courses, science related activities, and a short essay on their interest in the program. The number of applications received per year varied, averaging around 25, with a maximum of 24 students selected to participate in the program during the 2013, 2014, and 2015 summers, and 12 students selected for the 2016 summer. Student selection was based on prior course work (biology required), level of expressed interest in the program, and ability to commit the time necessary to complete the program. The program was comprehensive in that it integrated the following components: a) classroom lectures on biology and research, b) hands-on activities related to biology experiments, c) students as apprentices conducting a research project as part of a larger ongoing biomedical research study, d) preparation for college and careers in science, and e) student mentoring by scientists. All components occurred in authentic scientific settings (i.e., biomedical laboratory) at City of Hope.

Before students started the program activities and research in a biomedical laboratory, students participated in a three-week laboratory training course taught by the high school science teacher in his classroom. Topics and techniques covered included pipetting, plating cells, counting colonies, plasmid manipulations, serial dilutions, how to make solutions, metric system conversions, and a review of the scientific method. This course offered foundational knowledge and skills that prepared students for the rigors of the summer research program.

The science activities, research, and mentoring in the biomedical laboratory lasted eight-weeks during the summer, meeting two days per week for three hours per day. The program was taught by a male $\mathrm{PhD}$ staff scientist at City of Hope, a female local $\mathrm{PhD}$ college professor, and a male high school science teacher from Duarte High School, who were recruited during the grant writing process for their experience with mentoring, experience with the target population for the program, and experience with hands-on science education. The program was designed to teach students about biological sciences, including biotechnology, microbiology, genetics, and biomedical topics. During the course of the program there were opportunities for close interaction between students and researchers (i.e., mentoring), which included weekly research talks and conversations about college, careers in science, and biomedical research. These talks were hosted largely by the instructors, but other scientists at City of Hope participated, including the Principal Investigator of a cancer research laboratory. Mentoring occurred at both the group and individual levels. Instruction was provided at the group level, with time for individual assistance incorporated into the curriculum. 
The summer program curriculum focused on the study of a protein used in DNA repair. Using yeast as a model system, students learned how to create two-hybrid plasmids, plate diluted cultures, and perform an ectopic gene conversion assay to test the effectiveness of the protein in homologous recombination and repair. Students also studied the form and function of each mutant variant of the protein through a Direct Repeat Recombination Assay. The data collected contributed to a research project in a laboratory at City of Hope, in which the instructor was a staff scientist, studying DNA repair mechanisms and their connection to cancer development. Therefore, the program and specific activities were directly integrated into the work of a real ongoing research study at the cancer center in order to increase the likelihood that students would feel a part of the scientific team and develop a stronger sense of what it meant to play a role in contributing to the process of science.

At the end of the eight weeks, students presented their research to a group of local city officials (e.g., City Mayor, City Council, and School Board Members), scientists, friends and family. Students were mentored on data analysis and interpretation, presentation development, communicating science to general audiences, and public speaking. Students also received a $\$ 400$ stipend for the work they contributed to the research project during the program. Upon completion of the program, interested students were offered the opportunity to continue research in various laboratories at City of Hope.

Evaluation Methodology. Evaluation of the SEPAC High School Summer Research Program was conducted with support from the Claremont Evaluation Center (CEC), housed at Claremont Graduate University. They have a longstanding history of designing and implementing evaluation tools for measuring educational programs. The data presented in the current paper is part of a broader evaluation approach that included quantitative and qualitative methods. The current paper focuses on the data collected from the pre-post program student survey and the longitudinal post-survey.

Pre-Post Student Survey. Participants across all cohorts completed the pre-survey as part of their application to the program in March and April, and then took the post-survey on the final day of the program in August. Pre and post surveys included the following four psychosocial construct measures: knowledge of pathways into science, self-efficacy in science, attitudes towards science, and scientific communication skills. The measures used were designed and implemented by the CEC team, utilizing metrics previously established and validated in literature (Chemers et al., 2011b; Goza and Bearman, 2011).

\section{Measures}

Knowledge of pathways into science. The measure of knowledge of pathways into science consisted of five items assessing understanding of career pathways and necessary steps to pursue a scientific field. Sample items included: "I know what topics I need to study in school to get my science career," and "I have a role model who is good in science." Each of the items was rated on a Likert-type 5-point scale from $1=$ Strongly Disagree to $5=$ Strongly Agree. The pre-survey reliability score was $\alpha=0.784$ while the post-survey reliability score was $\alpha=0.822$.

Self-efficacy in science. The measure of self-efficacy consisted of four items assessing participants' beliefs of their ability to conduct scientific tasks and successfully achieve scientific endeavors. Sample items included: "I believe I can master science-related knowledge" and "I could be a good scientist one day." Each of the items was rated on a Likerttype 5-point scale from $1=$ Strongly Disagree to $5=$ Strongly Agree. The pre-survey reliability score was $\alpha=0.883$ while the post-survey reliability score was $\alpha=0.912$.

Attitudes towards science. The measure of attitudes towards science consisted of four items assessing general attitudes towards the significance of science and learning science. Sample items included: "Scientists have a chance to make a positive difference in the world," and "Learning science makes my life more meaningful." Each of the items was rated on a Likert-type 5-point scale from 1 = Strongly Disagree to $5=$ Strongly Agree. The pre-survey reliability score was $\alpha=0.781$ while the post-survey reliability score was $\alpha=0.793$.

Scientific Communication skills. The measure of communication skills assessed skills related to comfort in communicating a research study and the findings with others, particularly focused on group communication and comfort while presenting in front of groups. The measure consisted of six items, rated on a Likert-type 5-point scale from $1=$ Strongly Disagree to $5=$ Strongly Agree. Sample items included: "I enjoy participation in class discussions" and "I think clearly when I am giving a presentation." The pre-survey reliability score was $\alpha=0.883$ while the post-survey reliability score was $\alpha=0.887$.

Longitudinal Follow-Up Post-Survey. Participants who attended the SEPA Summer Research Program during the summers of 2012, 2013, 2014, and 2015 were sent an online survey in 2016, and were asked to provide follow-up information on their college attendance, career aspirations and interests, and academic persistence. To assess students' academic interests, students rated 15 STEM-related topics. The 15 topics presented to students were: biomedical research, computer science, chemistry, biology research (marine, plant, etc.), pre-medicine, forensic science, engineering (aeronautical, electrical, mechanical, etc.), psychology, earth 
and space science (geology, astronomy, etc.), environmental studies, physics, science education (to teach science in middle or high school), nursing, pre-dentistry, and pre-veterinary science. Additionally, students were asked to respond to an open ended prompt on their ideal career, as well as the three following questions reflecting on program experience: 1) reflections on how the program has helped them in college, 2) whether there was anything additional they wished they had learned, and 3) any suggestions for improvement. In addition, students were asked to suggest additional program content/topics to be covered, and to provide any suggestions for overall program improvement.

Data Analyses. To assess the short-term improvement from pre-program to post-program, we conducted analyses combining the four summer cohorts (2013-2016). A set of non-parametric Wilcoxon signed-rank tests were conducted to test for a significant increase in scores from pre-program to post-program for each of the short-term psychosocial outcome measures: knowledge of pathways into science, self-efficacy in science, attitudes towards science, and scientific communication skills. We also conducted analyses to evaluate the long-term outcomes, such as participants' college status, academic and career interests, and academic persistence. We assessed the long-term outcomes in participants from four summer cohorts (2012-2015).

\section{RESULTS}

There were a total of 79 students who participated in the science program, and 58 of those students completed both pre and post program surveys for evaluation of short-term outcomes. The difference between participants and survey responders may be attributed to students being absent on the days of the surveys, or choosing not to participate, as taking the survey was optional. Of these students, 16 (27\%) were male and $42(73 \%)$ were female. Twenty-five (43\%) students identified as Latinx American, $10(17 \%)$ as Asian American, 7 (12\%) as African American, 7 (12\%) as Filipino American, 3 (5\%) as non-Hispanic White American, and 6 $(10 \%)$ as Mixed. Students were sophomores (rising juniors, $\mathrm{n}=18,31 \%$ ) and juniors (rising seniors, $\mathrm{n}=40,69 \%$ ), none were seniors, and none were freshmen (Table 1).

\section{Short-term Outcomes}

Knowledge of Pathways into Science. There was a marginally significant increase for the composite score of knowledge of science pathways from pre-survey $(\mathrm{M}=3.86$, $\mathrm{SD}=0.66)$ to post-survey $(\mathrm{M}=4.06, \mathrm{SD}=0.64), \mathrm{Z}=-1.900$, $\mathrm{p}=0.057$. Conducting the analyses for the individual items from this measure, there were two items that showed a marginal and significant increase from pre-survey to post-survey. The item "I know what topics I need to study in school to get my science career" showed a marginally significant
Table 1. Demographics for Participants with Short-term Psychosocial Outcomes, Cohorts 2013-2016.

\begin{tabular}{lllllll}
\hline $\begin{array}{l}\text { Cohort } \\
\text { Year }\end{array}$ & Female & Male & Latino & Non- Latino & Sophomore & Junior \\
\hline 2013 & 11 & 5 & 6 & 10 & 5 & 11 \\
2014 & 10 & 7 & 8 & 9 & 4 & 13 \\
2015 & 13 & 4 & 9 & 8 & 6 & 11 \\
2016 & 8 & 0 & 1 & 7 & 3 & 5 \\
\hline Total & 42 & 16 & 24 & 34 & 18 & 40 \\
\hline
\end{tabular}

increase from pre-survey $(\mathrm{M}=3.73, \mathrm{SD}=0.82)$ to post-survey $(M=3.95, S D=0.76), Z=-1.782, p=0.075$. The item "I have a role model who is good in science" showed a significant increase from pre-survey $(\mathrm{M}=3.46, \mathrm{SD}=0.99)$ to post-survey $(\mathrm{M}=3.83, \mathrm{SD}=1.09), \mathrm{Z}=-2.436, \mathrm{p}=0.015$ (Table 2).

Self-Efficacy in Science. Although there was a positive trend of an increase for the composite score of self-efficacy and most individual items, there was no statistically significant increase from pre-survey $(\mathrm{M}=3.92, \mathrm{SD}=0.69)$ to post-survey $(\mathrm{M}=3.94, \mathrm{SD}=0.76), \mathrm{Z}=-0.247$, ns. (Table 2).

Attitudes Towards Science. There was a positive increasing trend but no statistically significant increase for the composite score of attitudes towards science from pre-survey $(M=4.19, S D=0.59)$ to post-survey $(M=4.30, S D=$ $0.57), \mathrm{Z}=-1.529$, ns. The individual item "Learning science can make my life more meaningful" had a significant increase from pre-survey $(\mathrm{M}=3.76, \mathrm{SD}=0.90)$ to post-survey $(\mathrm{M}=4.03, \mathrm{SD}=0.79), \mathrm{Z}=-2.114, \mathrm{p}=0.035$ (Table 2).

Scientific Communication Skills. Opposite of what was expected, there was a marginally significant decrease for the composite score of communication skills from pre-survey $(\mathrm{M}=3.69, \mathrm{SD}=0.70)$ to post-survey $(\mathrm{M}=3.51, \mathrm{SD}=0.68)$, $\mathrm{Z}=-1.833, \mathrm{p}=0.067$. There were two individual items that showed a significant decrease from pre to post survey. The item "I am very relaxed when answering questions in class" had a significant decrease from pre-survey $(\mathrm{M}=3.74, \mathrm{SD}=$ $0.89)$ to post-survey $(\mathrm{M}=3.36, \mathrm{SD}=0.89), \mathrm{Z}=-2.469, \mathrm{p}=$ 0.014 . The item "I think clearly when I am giving a presentation" had a significant decrease from pre-survey $(\mathrm{M}=3.78$, $\mathrm{SD}=0.88)$ to post-survey $(\mathrm{M}=3.40, \mathrm{SD}=0.97), \mathrm{Z}=-2.840$, $\mathrm{p}=0.005$ (Table 2).

Long-term Outcomes. A total of 21 students across five summer cohorts (2012-2016) continued to develop their scientific knowledge and skills by participating in at least one semester of after-school research. During their research internships students contributed to ongoing scientific studies across various laboratories within City of Hope.

A longitudinal survey was sent via email to 64 participants of the summer research program from 2012, 2013, 2014, and 2015 cohorts, during April and August 2016. A total of $26(40.6 \%)$ of the 64 participants responded. Addi- 
Table 2. Pre and Post Program Scores for Psychosocial Measures, Cohorts 2013-2016.

\begin{tabular}{|c|c|c|}
\hline Psychosocial Outcome & Pre-Program Score, Mean (SD) & Post-Program Score, Mean (SD) \\
\hline Knowledge of Science Pathways & $3.86(.66)$ & $4.06(.64)+$ \\
\hline 1) Knowledge of topic for science career & $3.73(.82)$ & $3.95(.76)+$ \\
\hline 2) Knowledge of schooling for science career & $3.86(.94)$ & $4.05(.85)$ \\
\hline 3) Belief of realizing career goals & $4.39(.78)$ & $4.34(.66)$ \\
\hline 4) Can find someone to learn science career & $3.86(.98)$ & $4.12(.90)$ \\
\hline 5) Have role model in science & $3.46(.99)$ & $3.83(1.09)^{* *}$ \\
\hline Self-Efficacy in Science & $3.92(.69)$ & $3.94(.76)$ \\
\hline 1) People tell me I am good at science & $3.76(.82)$ & $3.81(.85)$ \\
\hline 2) Believe can master science knowledge & $4.02(.76)$ & $3.97(.90)$ \\
\hline 3) Believe can master science skills & $4.07(.75)$ & $4.10(.74)$ \\
\hline 4) Could be good scientist one day & $3.84(.88)$ & $3.88(.94)$ \\
\hline Attitudes Toward Science & $4.19(.59)$ & $4.30(.57)$ \\
\hline 1) Science courses will help achieve goals & $4.22(.70)$ & $4.28(.85)$ \\
\hline 2) Enjoy studying science & $4.22(.70)$ & $4.26(.69)$ \\
\hline 3) Learning science makes life more meaningful & $3.76(.90)$ & $4.03(.79)^{*}$ \\
\hline 4) Scientists can make positive diff in world & $4.55(.63)$ & $4.63(.56)$ \\
\hline Scientific Communication Skills & $3.69(.70)$ & $3.51(.68)+$ \\
\hline 1) Enjoy participating in class discussions & $3.79(.93)$ & $3.79(.89)$ \\
\hline 2) People understand what I am trying to say & $3.79(.74)$ & $3.72(.77)$ \\
\hline 3) Relaxed when answering questions & $3.74(.89)$ & $3.36(.89)^{* *}$ \\
\hline 4) Think clearly when giving presentation & $3.78(.88)$ & $3.40(.97)^{* *}$ \\
\hline 5) Easy to convey info during presentations & $3.64(.87)$ & $3.52(.73)$ \\
\hline 6) Enjoy presenting in front of others & $3.41(.96)$ & $3.26(.97)$ \\
\hline
\end{tabular}

Statistical significance levels when comparing pre and post program scores:,$+ p<0.10 ; *, p<0.05 ; * *, p<0.01$

tionally, follow-up phone calls were made between December 2016 and January 2017 to 41 participants who had not responded. Of these 41 participants, five responded to make a total longitudinal sample of 31 .

After analysis showed that there were no significant differences among response from the four cohorts, cohort data was pooled. Of the 31 respondents, $24(77.4 \%)$ indicated they were currently attending college. There were no significant differences in college attendance by ethnicity, gender, or cohort year. Of the 24 students currently attending college, 7 (30.4\%) reported being the first in their family to attend college. Seventeen of the students $(70.8 \%)$ reported attending a four-year college. Eighteen of the students attending college $(75.0 \%)$ expressed that they planned to continue their education after college by attending graduate school, medical school, or other academic programs. Of the 18 students planning to pursue additional education after college, $6(35.3 \%)$ reported they would pursue a doctorate degree (Table 3).

Nineteen students (79.2\%) indicated a STEM related major (Table 3). The most common major was biology
$(52.9 \%)$, followed by bioengineering $(17.6 \%)$, computer science $(17.6 \%)$, and animal science $(11.8 \%)$. To assess students' academic interests, students rated 15 STEM-related topics. The highest rated STEM-related topic was biomedical research, followed by computer science, chemistry, biology research, and pre-medicine. Interest in STEM-related topics was significantly higher among first generation college students $(\mathrm{M}=2.48, \mathrm{SD}=0.63, \mathrm{n}=7)$, than students who were not first generation $(\mathrm{M}=1.88, \mathrm{SD}=0.10, \mathrm{n}=15)$, Kruskall-Wallis Test $=7.78, \mathrm{p}=0.02$. Furthermore, Latinx students $(\mathrm{M}=2.38, \mathrm{SD}=0.60, \mathrm{n}=10)$ indicated significantly higher interest in studying STEM-related topics than non-Latinx students $(\mathrm{M}=1.93, \mathrm{SD}=0.47, \mathrm{n}=13), \mathrm{p}<.05$.

An assessment of students' academic persistence in college indicated participants rated highly most of each of these 5 items: 1) I am smart enough to finish college, 2) I will graduate from college, 3 ) I can pick the right things to study in college, 4) I can successfully do the classwork and homework assignments in college classes, and 5) I like being in college (Composite $\mathrm{M}=4.10, \mathrm{SD}=0.76, \mathrm{n}=24$ ). The students rated these statements using the Likert-type five-point 
scale from $1=$ Strongly Disagree, to $5=$ Strongly Agree. Their highest level of agreement was with the items "I am smart enough to finish college" and "I will graduate college."

Student responses to the open-ended questions were evaluated and the most common responses were listed. In response to the question of their ideal job, the most common responses included laboratory researcher (29.6\%) and careers in the medical field (doctors/nurses, 29.6\%). Three overarching themes arose from the three questions reflecting on program experience: participants felt that the program helped them (1) determine their educational and career focus, (2) prepare for college courses, and (3) build specific skills that were helpful in college. An additional three comments $(11.1 \%)$ fell into an "other" category. When asked what additional content students thought should be added to the program, $71.4 \%$ indicated that there was no additional content they wished the program had covered. The remaining comments were split into the following two content themes: (1) career specific and (2) skill and content specific topics. Twenty-six students shared comments of ways to improve the program overall. Of these, $53.8 \%$ would not change anything about the program. The remainder of the comments fit into the following two common themes: (1) extending the length of the program and (2) skill building.

\section{DISCUSSION}

Diverse racial/ethnic minority groups continue to be underrepresented in the field of biomedical science, along with other scientific areas. A comprehensive science education that integrates multiple components addressing the multiple aspects of learning science - technical knowledge, collaborative or interpersonal interactions, and psychological/ behavioral experiences associated with development and growth as a scientist, is critical (Ashley et al., 2017; Salto et al., 2014). Furthermore, science education programs that offer mentorship and supportive role models providing guidance in conducting research in "authentic scientific" settings, offers underrepresented students opportunities to build the confidence and skills they need as a future scientist (Rohrbaugh and Corces, 2011; Salto et al., 2014; Wallace et al., 2015). Exposure to these types of scientific environments and research are crucial to demystifying the process of science and the role biomedical scientists play in advancing knowledge in various areas of science and healthcare practice (Aschbacher et al., 2009; Hsu and Roth, 2010; White and Usher, 2015). This type of exposure can also develop the psychosocial skills of students, which can be critical to prepare them to pursue higher education and careers in science or medicine.

There was a positive trend from pre to post program for three of the psychosocial short-term outcomes - knowledge of career pathways in science, self-efficacy in science, and
Table 3. Long-term Outcomes, Cohorts 2012-2015

\begin{tabular}{ll}
\hline Long-term Outcome & Percentage $(\mathrm{n}=31)$ \\
\hline Attending college & $77.4 \%$ \\
First in family attending college & $30.4 \%(\mathrm{n}=24)$ \\
Attending four-year college & $70.8 \%$ \\
Plan to pursue more education after college & $75.0 \%$ \\
Plan to pursue doctorate degree & $35.3 \%(\mathrm{n}=18)$ \\
Majoring in STEM degree & $79.2 \%$ \\
\hline
\end{tabular}

attitudes toward science. The post-program score increased, approaching statistical significance, for the outcome of knowledge of career pathways in science. One of the items in this outcome measure did show a statistically significant increase for the post-program score. Specifically, students reported that after the program they more strongly agreed that they had a role model in science compared to before the program. This observation is supported by the post-program results that showed a more than $44 \%$ increase in student's belief that they can identify with a role model that is good in science. Other previous studies have similarly found that relatively brief science programs increased the exposure to and interaction of students with scientists who they considered role models (Crump et al., 2015; Hsu and Roth, 2010). For students from underrepresented backgrounds who often do not have close interactions with others doing work in science, having a role model in science can be a "game changer" and enhance the possibility for students to identify with scientists or science in general, viewing a career in science as a "real possibility."

In general, students reported an increased self-efficacy in doing science, but the change was not significant. One possibility for the lack of a significant change is the use of a non-validated measure of self-efficacy. Another possibility is the length of the program: the program may not have been sufficiently long enough to substantially build the skills and self-confidence the students would need as scientists. However, the fact that several students were motivated enough to participate as research apprentices in laboratories at City of Hope after the summer program, and the nearly $80 \%$ of responding students reporting a college major in the sciences, demonstrates that for these students it is highly likely that the program encouraged development of their scientific competencies and confidence. The value of a brief hands-on summer science program lies in not only the improvement of psychosocial factors or research skills, but in spurring the action of students to pursue other science education opportunities. The psychosocial outcome of attitudes toward science also showed a positive trend post-program participation, with one single item showing a significant increase. Specifically, students reported that after the program they felt more strongly about the purpose of science, particularly that "learning science can make life more meaningful."

The outcome of scientific communication skills showed 
the opposite change of what was expected. Students' scientific communication skills, including level of comfort with responding to questions and delivering a presentation in a group setting decreased after the program. Although it is not clear why this was the case, it might be related to the fact that the post-survey was completed just after students did their group presentation on their research projects. The level of anxiety tied to the group presentation format was likely more conscious at the time students completed the measure of communication skills, influencing how they responded to the questions. Additionally, it is important to note that several questions assessing communication skills, including the two single items that showed a decrease, tap into the affective experience of communication within a group setting. Students were instructed as to how to prepare and present their data to an audience with a range of skill levels and expertise, with emphasis placed on understanding the data, presentation preparation, and presentation practice with their peers. While the science program aimed to improve the communication ability of students in group settings, it also increased the exposure of students to these settings, resulting in students not only presenting to their peers, but to scientists. Many students had limited experience presenting research and especially doing so in front of scientists. This finding is therefore instructive about how to improve the science program in the future, to work closely with students toward improving their comfort and confidence when giving research presentations. It indicates the importance of earlier and better preparation for students to present to an audience of not only peers but scientists.

In addition to examining program effects on short-term outcomes, an assessment of long-term outcomes revealed some reassuring evidence. First, several students went on to participate in at least one semester of an after-school research apprenticeship at City of Hope, following the end of their summer research program. Specifically, across the summer research cohorts, there were a total of $21(36 \%)$ students who continued strengthening their scientific knowledge and skills as well as interacting closely with research mentors. Second, 24 students $(77 \%)$ reported to have attended or be attending college at the time of the longitudinal assessment. On average, $78 \%$ of Duarte High School students attend higher education after graduation, with $25 \%$ attending a four year college or university, and $53 \%$ attending a community college. Third, most students $(75 \%)$ who reported being in college also expressed plans to pursue additional higher education by attending graduate school, medical school, or other professional education. Fourth, most students (79\%) indicated that they majored in a STEM related field. Interestingly, first-generation college students and Latinx students both expressed greater interest in studying STEM related topics compared to non-Latinx and non-first-generation college students. These findings offer evidence that some first-gen- eration college students and Latinx students are interested in science, and for those who are supported early may help them succeed at the various stages as they go through the pathway toward a career in science.

Limitations. The study has some limitations that should be noted. The results should be interpreted with caution regarding cause and effect, i.e., attributing to the science program the changes in outcomes, college attendance, or majoring in STEM fields. The research design did not include a control group of students who were not in a science program and thus any results post-program could be related to other factors not examined in the current study. Also, although the psychosocial measures exhibited reliability they were not rigorously tested for validity and each measure only had a few items. It is important to note that although the program was comprehensive and aimed to increase not only technical scientific skills but psychosocial skills, the program implementation and mentoring could have been more intentionally designed to specifically improve the psychosocial outcomes assessed, perhaps by including more activities focused on reflection. This limitation in program design could have contributed to the limited significant changes in psychosocial outcomes. It is also important to state that the students participating in the summer program are in general a self-selective group of students who are more interested and motivated in science compared to other students in their community who were not interested in participating in the program. In addition, the students who self-selected by applying to and participating in the program may have been more likely than their peers to pursue degrees and careers in STEM regardless of their participation in the program. Therefore, the results may not generalize to other subgroups of underrepresented adolescents. Additionally, the total sample size across cohorts was relatively small and therefore there was an issue with having the power to detect significant results. However, the finding of a positive trend toward increasing scores for all psychosocial outcomes, except for scientific communication skills, is encouraging. In regard to the longitudinal surveying, it is important to note that there may have been the influence of a self-selecting bias. Additionally, because the data was coded, we have limited information about students who did not respond. The variation in the amount of time between participation in the program and responding to the survey may have additionally impacted responses amongst participants. It is also noted that a significant limitation may be the use of a third party, CEC, to conduct the evaluations and surveys, as the students had no prior interaction with this team. Students may not have felt comfortable providing responses to this team; in the future it may be beneficial for the evaluations to be done in-house, using a team that the students have interacted with previously. 


\section{CONCLUSION}

In conclusion, participants in the summer research program showed some improvements in the relevant psychosocial short-term outcomes that evaluations of other science programs have also shown to improve post-program. There were positive trends in increased knowledge of pathways in science, attitudes toward science, and self-efficacy in science. Importantly, after the program, students were more likely to report that they had a role model in science. Research has found that most underrepresented minority students have few role models who are scientists and thus are also less likely to identify mentors who could encourage and support them in developing as a young scientist (Patel, 2015; Ramirez and Tonidandel, 2009). The summer research program increased the exposure of underrepresented minority students, several whom were Latinx, to researchers who they could identify with, learn from, and receive continuous encouragement from. Many students after the summer program continued to participate in after school research apprenticeships at the cancer center contributing to ongoing or new research in biomedical labs. Therefore, our comprehensive science apprenticeship program showed strengths in addressing one of the most significant gaps in supporting underrepresented minority students to become scientists, which are mentorship and the engagement with scientist role models. Furthermore, when examining long-term outcomes, a little over three-quarters of participating students continued toward higher education and most majored in STEM related fields.

\section{AUTHOR INFORMATION \\ Corresponding Author}

Christopher Sistrunk, Population Sciences Department, City of Hope, Duarte, California 91010. Contact: csistrunk@ coh.org.

\section{Author Contributions}

The manuscript was written through contributions of all authors. All authors have given approval to the final version of the manuscript.

\section{FUNDING SOURCES}

This science education initiative and evaluation was supported by a National Institutes of Health Science Education Partnership Award (SEPA-R25).

\section{ACKNOWLEDGMENTS}

We thank Dr. Tarek Azzam, Agnieszka Rykaczewska, Tiffany McBride, Courtney Koletar, Leslie Acuna, Samantha Langan, Ashley Hunt, Sonal Khosla, and the rest of the
Claremont Evaluation Center team members for their work to develop, implement and complete the evaluation of the San Gabriel Valley Science Education Partnership Award Collaborative (SGV SEPAC) High School Summer Research Program. We also thank the teachers, administrators, and students from Duarte Unified School District who supported and participated in the SEPAC program.

\section{ABBREVIATIONS}

CEC: Claremont Evaluation Center; DUSD: Duarte Unified School District; ns: not significant; SD: Standard Deviation; SGV SEPAC: San Gabriel Valley Science Education Partnership Award Collaborative.

\section{REFERENCES}

Asai, D. J., and Bauerle, C. (2016). From HHMI: Doubling down on diversity. CBE Life Science Education, 15(3). doi:10.1187/ cbe.16-01-0018.

Aschbacher, P. R., Li, E., and Roth, E. J. (2009). Is science me? High school students' identities, participation and aspirations in science, engineering, and medicine. Journal of Research in Science Teaching, 47(5), 564-582.

Ashley, M., Cooper, K. M., Cala, J. M., and Brownell, S. E. (2017). Building better bridges into STEM: A synthesis of 25 years of literature on STEM summer bridge programs. CBE Life Science Education, 16(es3), 1-18.

Bandura, A. (2001). Social cognitive theory: an agentic perspective. Annual review of psychology, 52, 1-26.

Burgin, S. R., Sadler, T. D., and Koroly, M. J. (2012). High school student participation in scientific research apprenticeships: variation in and relationships among student experiences and outcomes. Research Science Education, 42, 439-467. doi:10.1007/s11165-010-9205-2.

Byars-Winston, A., Estrada, Y., Howard, C., Davis, D., and Zalapa, J. (2010). Influence of social cognitive and ethnic variables on academic goals of underrepresented students in science and engineering: a multiple-groups analysis. Journal of Counseling Psychology, 57(2), 205-218.

Byars-Winston, A., and Rogers, J. G. (2019). Testing intersectionality of race/ethnicity $\mathrm{X}$ gender in a social-cognitive career theory model with science identity. Journal of Counseling Psychology, 66(1), 30-44.

Chemers, M. M., Zurbriggen, E. L., Syed, M., Goza, B. K., and Bearman, S. (2011a). The role of efficacy and identity in science career commitment among underrepresented minority students. Journal of Social Issues, .67(3), pp. doi:10.1111/j.1540-4560.2011.01710.x.

Chemers, M. M., Zurbriggen, E. L., Syed, M., Goza, B. K., and Bearman, S. (2011b). The role of efficacy and identity in science career commitment among underrepresented minority students. Journal of Social Issues, 67(3), 469-491. 
Crump, C., Ned, J., and Winkleby, M. A. (2015). The Stanford Medical youth science program: educational and science-related outcomes. Advances in Health Sciences Education, 20, 457-466.

Ed-Data.org (2019) Data from the California Department of Education, retrieved from Ed-Data.org on August 1st, 2019.

Fields, D. A. (2009). What do students gain from a week at science camp? Youth perceptions and the design of an immersive research-oriented astronomy camp. International Journal of Science Education, 32(2), 151-171.

Garrison, H. (2013). Underrepresentation by race-ethnicity across stages of U.S. science and engineering education. CBELife Sciences Education, 12, 357-363.

Hsu, P. L., and Roth, W. M. (2010). From a sense of stereotypically foreign to belonging in a science community: Ways of experiential descriptions about high school students' science internship. Research Science Education, 40, 291-311.

Knox, K. L., Moynihan, J. A., and Markowitz, D. G. (2003). Evaluation of short-term impact of a high school summer science program on students' perceived knowledge and skills. Journal of Science Education and Technology, 12(4), 471-478.

Lippke, S., and Ziegelmann, J. P. (2008). Theory-based health behavior change: Developing, testing, and applying theories for evidence-based interventions. Applied Psychology, 57(4), 698-716.

Mercer-Mapstone, L. K., Louise (2017). Core skills for effective science communication: A teaching resource for undergraduate science education. International Journal of Science Education, Part B, 7(2), 181-201.

Morales-Doyle, D. (2017). Justice-centered science pedagogy: A catalyst for academic achievement and social transformation. Science Education, 101(6), 1034-1060.

National Research Council. 2007. Taking Science to School: Learning and Teaching Science in Grades K-8. Washington, DC: The National Academies Press.

Newcombe, N. S., Ambady, N., Eccles, J., Gomez, L., Klahr, D., Linn, M., Miller, K., and Mix, K. (2009). Psychology's role in mathematics and science education. American Psychologist, 64(6), 538-550.

Patel, S. I., Rodriguez, P., and Gonzales, R. J. (2015). The implementation of an innovative high school mentoring program designed to enhance diversity and provide a pathway for future careeres in healthcare related fields. Journal of Racial and Ethnic Health Disparities, 2(3), 395-402. doi:10.1007/ s40615-015-0086-y.

Rahm, J., and Moore, J. C. (2016). A case study of long-term engagement and identity-in-practice: Insights into the STEM pathways of four underrepresented youths. Journal of Research in Science Teaching, 53(5), pp. doi:10.1002/ tea. 21268

Ramirez, J. J., and Tonidandel, S. (2009). SOMAS-URM: The evolution of a mentoring and summer research program. The Journal of Undergraduate Neuroscience Education, 8(1), A69-A72.
Richardson, D. M., Keller, T. E., Wolf, D. S. S., Zell, A., Morris, C., and Crespo, C. J. (2017). BUILD EXITO: a multi-level intervention to support diversity in health-focused research. BMC Proceedings, 11(12), 133-148.

Robinson, K. A., Perez, T., Nuttall, A. K., J., R. C., and Linnenbrink-Garcia, L. (2018). From science student to scientist: Predictors and outcomes of heterogeneous science identity trajectories in college. Developmental Psychology, 54(10), 1977-1992.

Robnett, R. D., Chemers, M. M., and Zurbriggen, E. L. (2015). Longitudinal associations among undergraduates' research experience, self-efficacy, and identity. Journal of Research in Science Teaching, 52(6), 847-867.

Rogers-Chapman, M. F. (2014). Accessing STEM-focused education: Factors that contribute to the opportunity to attend STEM high schools across the United States. Education and Urban Society, 46(6), pp. doi:10.1177/0013124512469815.

Rohrbaugh, M. C., and Corces, V. G. (2011). Opening pathways for underrepresented high school students to biomedical research careers: the Emory University RISE program. Genetics, 189(4), 1135-1143.

Sadler, T. D., Burgin, S., McKinney, L., and Ponjuan L. (2010). Learning science through research apprenticeships: a critical review of the literature. Journal of Research in Science Teaching, 47(3), 235-256.

Saetermoe, C. L., Chavira, G., Khachikian, C. S., Boyns, D., and Cabello, B. (2017). Critical race theory as a bridge in science training: the California State University, Northridge BUILD PODER program. BMC Proceedings, 11(12), 4155.

Salto, L. M., Riggs, M. L., De Leon, D. D., Casiano, C. A., and De Leon, M. (2014). Underrepresented minority high school and college students report STEM-Pipeline sustaining gains after participating in the Loma Linda University Summer Health Disparities Research Program. PLoS One, 9(9), 1-13.

Spektor-Levy, E., and Scherz, Z. (2009). Teaching scientific communication skills in science studies: Does it make a difference? International Journal of Science and Mathematics Education, 7(5), 875-903.

Stake, J. E., and Mares, K. R. (2005). Evaluating the impact of science-enrichment programs on adolescents' science motivation and confidence: The splashdown effect. Journal of Research in Science Teaching, 42(4), 359-375.

Templin, M. A., Doran, R. L., and Engemann, J. F. (1999). A locally based science mentorship program for high achieving students: Unearthing issues that influence affective outcomes. School Science and Mathematics, 99(4), 205-2012.

Upshur, C. C., Wrighting, D. M., Bacigalupe, G., Becker, J., Hayman, L., Lewis, B., Mignon, S., Rokop, M.E., Sweet, E., Torres, M.I., Watanabe, P., and Woods, C. (2017). The Health Equity Scholars Program: Innovation in the leaky pipeline. Journal of Racial and Ethnic Health Disparities, 5(2), 342-350. doi:10.1007/s40615-017-0376-7. 
Wallace, E. W., Perry, J. C., Ferguson, R. L., and Jackson, D. K. (2015). The careers in health and medical professions program (CHAMPS): An impact study of a university-based STEM+H outreach program. Journal of Science Education Technology, 24, 484-495. doi:10.1007/s10956-014-95362.

White, A. M., DeCuir-Gunby, J. T., and Kim, S. (2019). A mixed methods exploration of the relationships between the racial identity, science identity, science self-efficacy, and science achievement of African American students at HBCUs. Contemporary Educational Psychology, 57, 54-71.

White, H. B. I., and Usher, D. C. (2015). Engaging novice researchers in the process and culture of science using a "pass-the-problem" case strategy. Biochemistry and Molecular Biology Education, 43(5), 341-344.

Winkleby, M., and Ned, J. (2010). Promoting science education. Journal of the American Medical Association, 303(10), 983-984.

Winkleby, M. A., Ned, J., Ahn, D., Koehler, A., Fagliano, K., and Crump, C. (2014). A controlled evaluation of a high school biomedical pipeline program: Design and methods. Journal of Science Education and Technolology, 23(1), 138144. 